\title{
Comparison of soil water-contents as measured with a neutron probe and time domain reflectometry in a Mediterranean forest ("Sierra de Gata", Central Western Spain)
}

\author{
María Amparo Vicente ${ }^{\mathrm{a}}$, Juan Fernando Gallardo ${ }^{\mathrm{a} *}$, Gerardo Moreno $^{\mathrm{b}}$ and María Isabel González ${ }^{\mathrm{c}}$ \\ ${ }^{a}$ Consejo Superior de Investigaciones Científicas, Aptdo. 257, Salamanca 37071, Spain \\ ${ }^{\mathrm{b}}$ Centro Universitario, Universidad de Extremadura, Plasencia 10600, Cáceres, Spain \\ c Área de Edafología, Universidad de Salamanca, Salamanca 37080, Spain
}

(Received 12 December 2001; accepted 27 November 2002)

\begin{abstract}
The present work compares the results obtained with two indirect techniques (neutron probe and time domain reflectometry, TDR) for measuring soil water contents $(\theta)$ at different depths on an experimental plot in the "Sierra de Gata" (Central Western Spain). At the same time, the temporal and spatial evolution of $\theta$ was assessed in the zone studied. Measurements were made over three years (from September 1996 to August 1999). The results point to a good correlation $(r=0.98)$ between $\theta$ measured with both techniques, although TDR slightly (but significantly; $P<0.01)$ underestimated the $\theta$ values, but only during the drying periods and with low $\theta$ values. Non-significant differences between both methods were found for the estimation of soil water contents in the whole soil profile. Accordingly, both techniques are interchangeable and it is thus possible to avoid the potential risk of radioactivity. Considerable inter-annual variability was observed in the soil water content, governed by the annual rainfall distribution. A "flowing-off" effect was observed, followed by a progressive re-wetting of the soil profile from the bottom. Both the temporal and spatial variabilities of soil water content were found to decrease with depth.
\end{abstract}

soil water-content / neutron probe / TDR / oak forests / Western Spain / Mediterranean climate

Résumé - Comparaison des mesures de teneurs en eau du sol effectuées par sonde à neutrons et TDR dans une forêt méditerranéenne ( Sierra de Gata », Espagne Centre-Ouest). Le présent travail avait pour objectif de comparer deux méthodes indirectes de mesure de la teneur en eau $(\theta)$ du sol : sonde à neutrons et TDR (Time Domain Reflectometry) dans le cas d'une parcelle forestière située dans la «Sierra de Gata », région du Centre-Ouest de l'Espagne. Les aspects de variabilités temporelle et spatiale ont été également abordés. Une campagne de mesures s'est poursuivie de septembre 1996 jusqu'à août 1999, soit près de 3 ans. Les résultats obtenus montrent une bonne corrélation $(r=$ $0,98)$ entre $\theta$ mesurées avec les deux techniques. L'estimation de la teneur en eau du sol pour l'ensemble du profil montre des différences non significatives $(P>0,05)$, bien que le TDR sous-estime légèrement (mais de façon significative $; P<0.01)$ les valeurs de $\theta$ seulement quand le sol s'assèche et pour des valeurs de $\theta$ faibles. Les deux techniques sont donc a-priori interchangeables et il est donc possible d'envisager le remplacement des méthodes nucléaires et d'éviter ainsi les risques correspondants. Sur le plan de l'hydrologie, on a constaté une variabilité, temporelle et spatiale, décroissante avec la profondeur du sol et une considérable variabilité inter-annuelle liée aux fluctuations du régime des pluies. Enfin, un phénomène de transfert rapide vers le bas suivi d’une réhumectation par inhibition vers le haut a été également mis en évidence.

humidité du sol / sonde à neutrons / TDR / chênais / Espagne occidentale / climat mediterranéen

\section{INTRODUCTION}

The soil water content is a key factor in the functioning of terrestrial ecosystems, being of fundamental importance to many hydrological, biological and biogeochemical processes. In particular, the soil water content provides useful information about the actual evapotranspiration, drainage, and leaching [14]. Over the past decade, interest in water fluxes in natural ecosystems has increased owing to the appearance of evidence of changes in the annual distribution of rainfall and a hypothetical reduction in the actual evapotranspiration as a consequence of the global change $[4,21]$, and also hydrological changes induced by water management [1]. The need for such knowledge is most important in Mediterranean areas, where water is frequently the first limiting factor to plant growth [20].

The accuracy of the information derived from soil water measurements depends on the time and space scales of soil moisture measurements [7, 14]. Many methods can be used to measure soil water contents, and they can be classified as direct or indirect [11].

\footnotetext{
${ }^{*}$ Correspondence and reprints

Tel.: (34) 923219606; fax: (34) 923219609; e-mail: jgallard@ usal.es
} 
Direct methods require the collection of soil samples from the field each time it is desired to know the moisture content. However, the need for successive soil sampling leads to an irreversible alteration of the soil profile (increasing the number of core holes with time), which can eventually affect the real water-flow inside of the original soil-profile. Also, the measurements cannot be repeated at the same point and it is therefore necessary to monitor the spatial variability very precisely in order to be able to study variations occurring with time. Although these direct methods are destructive and very high time-consuming, they afford very precise measurements of the soil-water content, and (usually the thermo-gravimetry method) are therefore used in the calibration of indirect methods.

Indirect or non-destructive methods are based on the measurement of a physical property of the soil that depends on the soil-water content. Sensors permanently installed in the soil are used and these must be connected to a measuring unit each time measurements are made; alternatively, soil sensors are placed using an access tube (previously installed in the ground) each time measurements are to be made. Such successive measurements taken over time do not destroy the soil, although they often require tedious prior calibrations. The most widely used non-destructive indirect methods are [34] the neutron-probe technique, dielectric methods (timedomain reflectometry and capacitance techniques), electricalresistance methods, thermal conductivity (heat dissipation), and gypsum blocks.

The neutron-probe method has been widely implemented and is currently used as an acceptable method [5] and indeed is sometimes used as the reference method. However, apart from the need for special precautions against radioactivity, this method is sensitive to bulk soil density, a calibration for each soil type and each soil horizon being necessary [5]. Another important disadvantage of the use of the neutron probe (NP) is the difficulty involved in its automation, which has prevented generalisation of the technique [34].

More recently, time domain reflectometry (TDR) has been the method most widely used, and it is currently displacing other "classic" methods used to measure soil water contents owing its reliability and handling speed [26]. The TDR technique is based on measurement of the soil dielectric constant $\left(K_{\mathrm{m}}\right)$. To achieve this, a high frequency electromagnetic pulse is sent into the soil through a waveguide. When this step encounters impedance mismatches at the end of the probe, or at the interface between regions of different permittivities, part of the signal is reflected back and the apparatus detects and processes this signal. The speed of propagation of this wave depends on the dielectric soil permittivity of the medium $\left(K_{\mathrm{m}}\right)$ :

$$
t=2 L K_{\mathrm{m}}^{1 / 2} / c
$$

where $t$ is the round-trip time, $L$ is the wave-guide length, and $c$ is the velocity of the electromagnetic waves in free space. The term $c t / 2$ can be reduced to an apparent probe length $(L a)$, where $L a$ is determined as the distance between reflections at the beginning and at the end of the probe [17].

Rearranging equation (1), $K_{\mathrm{m}}$ is then calculated as:

$$
K_{\mathrm{m}}=(\mathrm{La} / \mathrm{L})^{2} \text {. }
$$

$K_{\mathrm{m}}$ depends on the proportion of each soil phase (water, air and mineral solids).

The dielectric constant of water $\left(K_{\mathrm{w}}\right)$, which is temperature-dependent, ranges from 74 to 84 and is about 20fold higher than that of mineral solids (between 3 and 5), and about 80 -fold higher than that of air $\left(1.0005\right.$ at $20^{\circ} \mathrm{C}$ and $10^{5} \mathrm{~Pa}$ ). This large difference between the dielectric constant of water and the rest of the soil phases means that the $K_{\mathrm{m}}$ is highly sensitive to the water content [27].

Based on this, Topp et al. [27] proposed an empirical formula to calculate the volumetric water content from the soil dielectric constant as determined by TDR. This relationship has been widely used in the literature because of its assumed low sensitivity to soil bulk density [17]. Nevertheless, some authors have noted the poor reliability of this equation when working with soil types different from those initially used to determine it [10]. In this sense, Roth et al. [23] demonstrated that this equation is only valid for soils with apparent densities greater than $1.55 \mathrm{~g} \mathrm{~cm}^{-3}$, which is not the case for forest soils. Therefore, many other relationships were proposed and efforts must be made to validate them [17].

Most comparative studies addressing the techniques used for measuring soil water contents refer to comparisons of an indirect method with another direct one: traditionally gravimetry $[18,19,25,28]$. The literature contains very few references to works that compare different indirect methods in the field $[8,13,33]$. Accordingly, the aim of the present work was to compare the results obtained in the measurement of soil-water contents obtained using a NP and TDR. At the same time, the temporal and spatial evolution of the soil-water content was studied at different depths in the research zone.

\section{MATERIALS AND METHODS}

\subsection{Study area}

The study area is located in the vicinity of "El Rebollar" ("Sierra de Gata", central-western Spain). The coordinates of the experimental plot are $40^{\circ} 2^{\prime} 40^{\prime \prime} \mathrm{N}, 3^{\circ} 0$ ' $50^{\prime}$ ' $\mathrm{W}$ and it is located at an altitude of $960 \mathrm{~m}$ above sea level. The soil types feature a predominance of haplic Umbrisols [3]. The vegetation comprises the Atlantic oak (Quercus pyrenaica). Further information can be found in tables I and II, and in Turrión et al. [29].

\subsection{Data collection: neutron probe}

A Troxler 3321A NP ( ${ }^{241} \mathrm{Am}: \mathrm{Be} 10 \mathrm{GBq}$ nuclear source) device was used. This system includes a ${ }^{3} \mathrm{He}$ detector to count thermalised neutrons (neutron exit activity $<0.005 \mathrm{GBq}$ ).

Measurements were taken in 12 PVC 6-cm diameter access tubes. These tubes had been introduced six years earlier (in 1990) into the ground down to the bedrock, to a maximum soil depth of $110 \mathrm{~cm}$ (ranging from -50 to $-110 \mathrm{~cm}$ ). Readings were taken every $20 \mathrm{~cm}$, from $-20 \mathrm{~cm}$ to $-100 \mathrm{~cm}$ (as referred to the centre of the measurements), taking into account the sphere of influence, which varies inversely with the water content, although an average $20-\mathrm{cm}$ diameter can be assumed [5].

Soil moisture readings were taken every 15 days from September 5th 1996 to August 19th 1998 and, thereafter monthly up to August 16th 1999. During March and April 1997 it was not possible to take 
Table I. Characteristics of the forest plot at Navasfrías (province of Salamanca, Western Spain).

\begin{tabular}{|c|c|}
\hline Relief: & Mountainous \\
\hline Physiography: & Slope, 5 to $15 \%$ \\
\hline Orientation: & East \\
\hline Altitude: & $960 \mathrm{~m}$ above sea level \\
\hline Climate: & Humid Mediterranean \\
\hline Mean annual rainfall: & $1580 \mathrm{~mm} \mathrm{a}^{-1}$ \\
\hline Mean annual temperature: & $10.4^{\circ} \mathrm{C}$ \\
\hline Potential evapotranspiration: & $800 \mathrm{~mm} \mathrm{a}^{-1}$ \\
\hline Bedrock: & Paleozoic, schists, grauwackes \\
\hline Rock outcrops: & Occasional \\
\hline Soil typology: & Haplic and Cambic Umbrisols \\
\hline Vegetation: & Quercus pyrenaica, Pteridium aquilinum, Cytisus scoparius, Erica australis \\
\hline Forest management: & Coppice \\
\hline Human influence: & Last thinning: 30 years ago \\
\hline Tree density: & 820 trees $\mathrm{ha}^{-1}$ \\
\hline Mean height of trees: & $13 \mathrm{~m}$ \\
\hline Mean D.B.H.: & $16.5 \mathrm{~cm}$ \\
\hline Foliar index: & $1.8 \mathrm{~m}^{2} \mathrm{~m}^{-2}$ \\
\hline Basal area: & $15.63 \mathrm{~m}^{2} \mathrm{ha}^{-1}$ \\
\hline Aboveground biomass: & $64.53 \mathrm{Mg} \mathrm{ha}^{-1}$ \\
\hline Mean annual aboveground production: & $2.60 \mathrm{Mg} \mathrm{ha}^{-1} \mathrm{a}^{-1}$ \\
\hline
\end{tabular}

(D.B.H.: diameter at breast height).

Table II. Forest soil properties of Navasfrías district (province of Salamanca, Western Spain).

\begin{tabular}{|c|c|c|c|c|}
\hline \multirow[t]{2}{*}{ Soil properties } & \multicolumn{4}{|c|}{ Soil horizons } \\
\hline & $A_{h 1}$ & $A_{h 2}$ & $\boldsymbol{B}_{w}$ & $C$ \\
\hline Depth $(\mathrm{cm})$ & $0-20$ & $20-40$ & $40-70$ & $>70$ \\
\hline Stones and gravels $(>2 \mathrm{~mm}, \%)$ & 32 & 39 & 48 & 42 \\
\hline Clay $(\%)$ & 18 & 18 & 17 & 20 \\
\hline Soil organic matter $(\%)$ & 17 & 11 & 1.0 & 0.5 \\
\hline Bulk density $\left(\mathrm{g} \mathrm{cm}^{-3}\right)$ & 0.7 & 0.9 & 1.2 & 1.4 \\
\hline Total porosity $\left(\mathrm{cm}^{3} \mathrm{~cm}^{-3}\right)$ & 0.65 & 0.63 & 0.60 & 0.48 \\
\hline Soil micro-porosity $\left(\mathrm{cm}^{3} \mathrm{~cm}^{-3}\right)$ & 0.33 & 0.30 & 0.32 & 0.36 \\
\hline Soil-water content $-1.5 \mathrm{MPa}\left(\mathrm{cm}^{3} \mathrm{~cm}^{-3}\right)$ & 0.18 & 0.15 & 0.10 & 0.15 \\
\hline Available water $\left(\mathrm{cm}^{3} \mathrm{~cm}^{-3}\right)$ & 0.15 & 0.15 & 0.22 & 0.21 \\
\hline Fine root length density $\left(\mathrm{cm} \mathrm{cm}^{-3}\right)$ & 6 & 4 & $<1$ & No data \\
\hline Fine root biomass $\left(\mathrm{mg} \mathrm{cm}^{-3}\right)$ & 6 & 4 & $<1$ & No data \\
\hline
\end{tabular}

readings due to problems with the authorities responsible for regulating the use of radioactive materials. Overall, data were collected on 52 occasions.

Surface moisture was determined gravimetrically, since using the NP for surface measurements $(<5 \mathrm{~cm})$ is rather tedious because reflectors must placed at the interface to prevent neutrons from escaping into the atmosphere [15], thereby artificially extending the measured soil volume. Twelve samples of about $100 \mathrm{~g}$ were taken on the same dates as the neutron probe measurements were recorded and were oven-dried for 24 hours.

The calibration curves for this specific site were determined from gravimetric samples and dry soil bulk densities, according to 


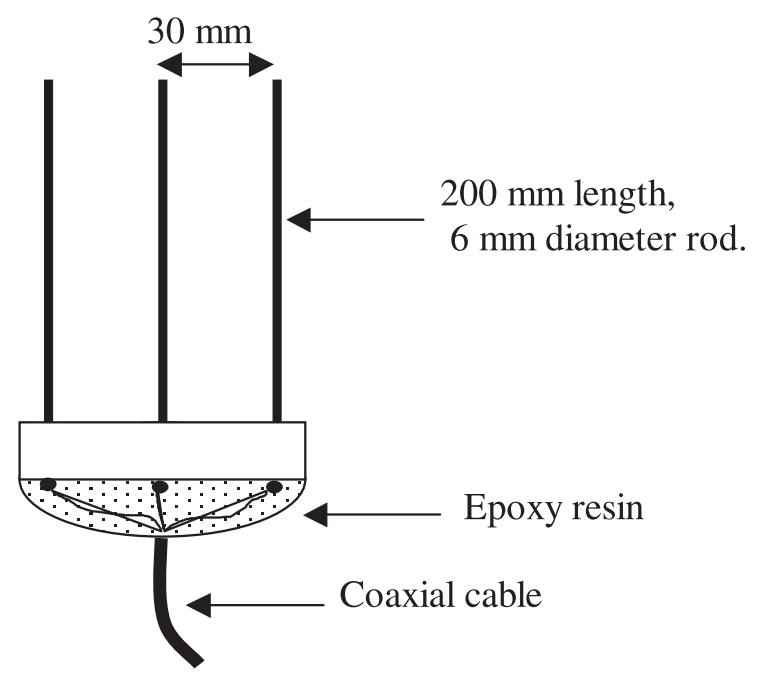

Figure 1. Diagram of the TDR sensor: three parallel rods.

Vachaud et al. [30]. Two set of data were used: soil cores, for the simultaneous determination of soil bulk-density, and gravimetric water-contents, were taken by digging around four additional access tubes. Each tube was digged on a different date, covering the different statuses of soil moisture contents.

Additionally, soil samples for water-content determination were taken with an auger near the twelve permanent access-tubes (between 1 and $2 \mathrm{~m}$ away) at the same depth as the NP readings, on different dates along three years (24 data per depth). Samples for the determination of soil bulk density were taken at the beginning of the study in three holes dug into the soil of the plot (two samples per hole).

\subsection{Data collection: TDR}

The TDR apparatus employed was a Tektronix model 1502C (metal cable tester), which was handled manually.

Sixteen sensors were constructed: each comprised three parallel rods (similar to a trident; figure 1) made of stainless steel, $200 \mathrm{~mm}$ in length and sharpened at one end to facilitate their introduction into the soil. Rod diameter was $6 \mathrm{~mm}$ and the separation between their axes $-30 \mathrm{~mm}$ - was chosen after Zegelin et al. [36]. The central rod was connected to the main conductor of a low ohm-resistance coaxial cable and the rods at either side were connected to the mesh of the cable. The probe thus simulates a coaxial cell, and does not need an impedance-matching transformer [17].

All connections were coated with an epoxy resin (Struers kit EPOFIX ${ }^{\circledR}$ ) which acted as an electrical insulator, at the same time firmly holding the rods in the parallel position.

The sixteen trident sensors were placed vertically in the soil at different depths: from 0 to $-20 \mathrm{~cm}$; from -20 to $-40 \mathrm{~cm}$; from -40 to $-60 \mathrm{~cm}$ and from -60 to $-80 \mathrm{~cm}$. Each sensor was separated from its neighbour by at least $50 \mathrm{~cm}$; that is, 4 sensors for each depth. During installation, efforts were made to ensure maximum contact between the rods and the soil.

To calculate soil moisture contents, we used a combination of the empirical and physical models proposed by Dobson et al. [2], modified by Roth et al. [24]. This type of model incorporates into its corresponding equation the contribution of each soil phase to the dielectric constant of the medium. Thus, it takes into account the effects of variations in other parameters, such as soil porosity and temperature. It is therefore well adapted when considering different soil types such as in the present study.

The equation used was [24]:

$$
\theta=\left[K_{\mathrm{m}}^{\alpha}-(1-\eta)\left(K_{\mathrm{s}}^{\alpha}-\eta\right)\right] /\left(K_{\mathrm{w}}^{\alpha}-1\right),
$$

where $\theta$ is the volumetric water content (in $\mathrm{cm}^{3} \mathrm{~cm}^{-3}$ ) of the soil; $K_{\mathrm{m}}$ is the relative soil dielectric-constant (adimensional); $K_{\mathrm{W}}$ is the relative water dielectric-constant (no unit); $K_{\mathrm{S}}$ is the relative dielectric constant of the mineral solids of the soil (a value of 4 was taken); $\eta$ is the soil porosity at each point $\left(\mathrm{cm}^{3} \mathrm{~cm}^{-3}\right)$, and $\alpha$ is the anisotropy coefficient of the medium. Based on experimental data, Jacobsen et al. [10] have shown that $\alpha$ varies between 0.4 and 0.8 , and Zakri et al. [35] demonstrated the physical meaning of this " $\alpha$-model" (based on the Effective Medium Theory). However, we assumed $\alpha=$ 0.5, following Dobson et al. [2] and Roth et al. [24], owing to the difficulty involved in obtaining a reliable determination of $\alpha$.

$K_{\mathrm{w}}$ was considered as a function of the soil temperature [32]:

$$
\begin{aligned}
K_{\mathrm{W}}= & 78.54\left[1-4.57910^{-3}(\mathrm{t}-25)+1.1910^{-5}(\mathrm{t}-25)^{2}\right. \\
& \left.-2.810^{-8}(\mathrm{t}-25)^{3}\right] .
\end{aligned}
$$

Soil temperature was measured with permanently buried thermistors protected in a stainless steel sheath (UNIDATA, model $6507 \mathrm{~A}$; resolution $\pm 0.5^{\circ} \mathrm{C}$ ). Sensors were located at $-10,-30$ and $-50 \mathrm{~cm}$ depth and were connected to a datalogger (UNIDATA, Starlog $7000 \mathrm{~B})$. Soil temperature at the $50-\mathrm{cm}$ depth was considered applicable for TDR probes located at -40 to $-60 \mathrm{~cm}$ depth and also for those located at -60 to $-80-\mathrm{cm}$ depth, owing to the limited soil temperature variation at such depths.

\subsection{Statistical analysis}

For comparative purposes, moisture measurements with TDR (55 dates) and NP (52 dates) were performed on the same days (51 times, 4 depths). Linear regression was applied to show the relationships between soil water contents measured with both methods. Similarly, linear regressions were applied at each depth.

To establish an overall comparison between the volumetric water content data measured with both methods, a $t$-test for paired data was used. The differences between both measuring methods at different depths were tested by means of two-way ANOVA, with depth as the between-sample factor, and method as the within-sample (repeated measurements) factor, using average values for each date, as the independent values. Similar analyses were applied to test the differences between the methods, considering four different ranges of volumetric water content $(0.07-0.14 ; 0.14-0.21 ; 0.21-0.28$ and 0.28 $0.35 \mathrm{~cm}^{3} \mathrm{~cm}^{-3}$ ) and, finally, considering different periods (wetting, steady-state, and drying). Tukey tests, with the Newman-Keuls' method, were used for multiple comparisons of means when significant differences were indicated by ANOVA, the differences being considered significant at $P<0.05$.

\section{RESULTS AND DISCUSSION}

\subsection{Neutron probe calibration}

The best linear relationships between the NP readings and volumetric water contents (thermogravimetry data multiplied by the soil bulk-density) were obtained by grouping the data in three different ranges of soil bulk density ( 0.85 to $1.25,1.26$ to 1.60 , and 1.60 to 2.00; figure 2) because of the direct influence of the soil bulk-density in neutron thermalization [5]. The results indicated that low soil water contents $(\theta)$ were slightly 


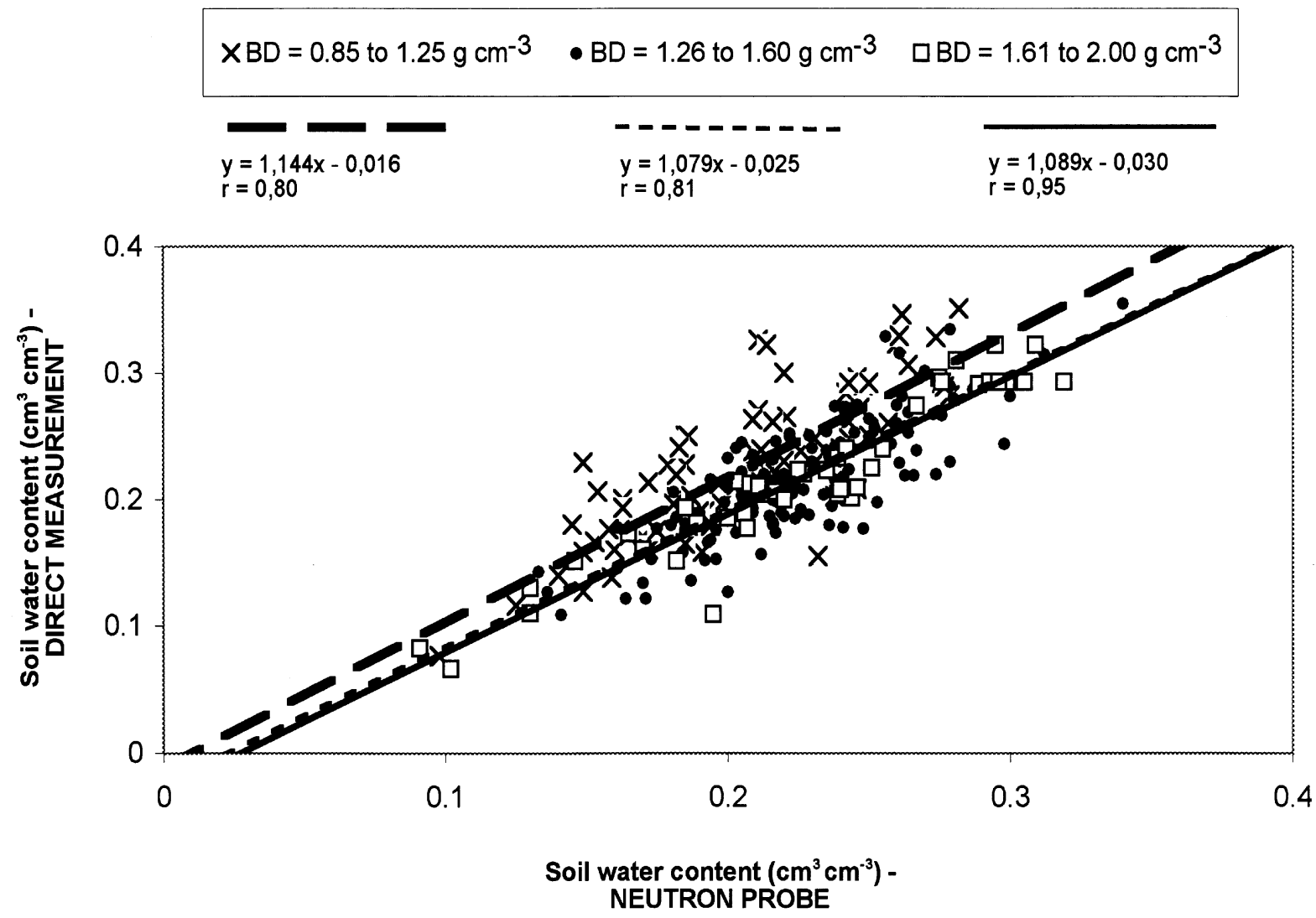

Figure 2. Results of the lineal regressions between soil-water content measured by a direct method (thermogravimetry) and by neutron probe (original calibration). Three groups of data were established in function of the soil bulk-density.

overestimated with the NP method, whereas high $\theta$ were slightly underestimated. At low densities, the bias was higher at high $\theta$, while at high densities the bias was higher at low $\theta$.

The variability not explained by these relationships $\left(r^{2}\right.$ even lower than 0.70 ) could be due to the high spatial variability of $\theta$ due, for instance, to the presence of stones or roots $[7,30]$ and to the fact that the gravimetric and NP data did not refer exactly to the same place. Moreover, soil samples for the gravimetric determination of water contents and those for the determination of bulk density were obviously not taken at exactly the same places (or dates).

Nevertheless, these three relationships (figure 2) were highly significant $(P<0.01)$. Thus, they were applied to the determination of the volumetric water content in the field and used also for the TDR calibration.

\subsection{Comparison between the NP and TDR techniques}

\subsubsection{Comparison between soil-profile moistures obtained with both methods}

On comparing the seasonal variation of water contents of the soil profile (considering the first $80 \mathrm{~cm}$ of soil) determined with both techniques (figure 3), non-significant differences were found: paired $-t$ test; $P>0.05 ; n=51$. This would theoretically demonstrate the possibility of replacing NP by TDR. Nevertheless, slight differences were still observed between both methods, with maximum and minimum values slightly higher and lower, respectively, with TDR than with NP.

Measurements of soil moisture carried out with both techniques were performed at different depths owing to methodological problems: $-20,-40,-60,-80$ and $-100 \mathrm{~cm}$ for the NP (assuming a sphere of $20 \mathrm{~cm}$-diameter); and 0-20, 20-40, 40-60 and 60-80 cm for TDR.

It is therefore not possible to make a very strict comparison of the results. In order to compare both methods, the mean values obtained with two consecutive NP-readings were used. That is, $\theta$ was calculated for instance at $20-40 \mathrm{~cm}$ as an average between the readings at -20 and $-40 \mathrm{~cm}$.

Figure 4 shows the linear relationships between the soilmoisture values obtained with both techniques. A highly significant correlation was obtained $(r=0.984 ; P<0.01 ; n=$ 51 measures $\times 4$ depths $=204$ ).

Other authors have made comparisons between the TDR technique and gravimetry, obtaining good correlations regardless of the calibration employed. Thus, Rabadá and Gallart [19] obtained a correlation coefficient of $r=0.997$. Gaskin and Miller [6], also using an electric method (an impedance analyser), also found good correlations $(r=0.986)$ for forest-floor 

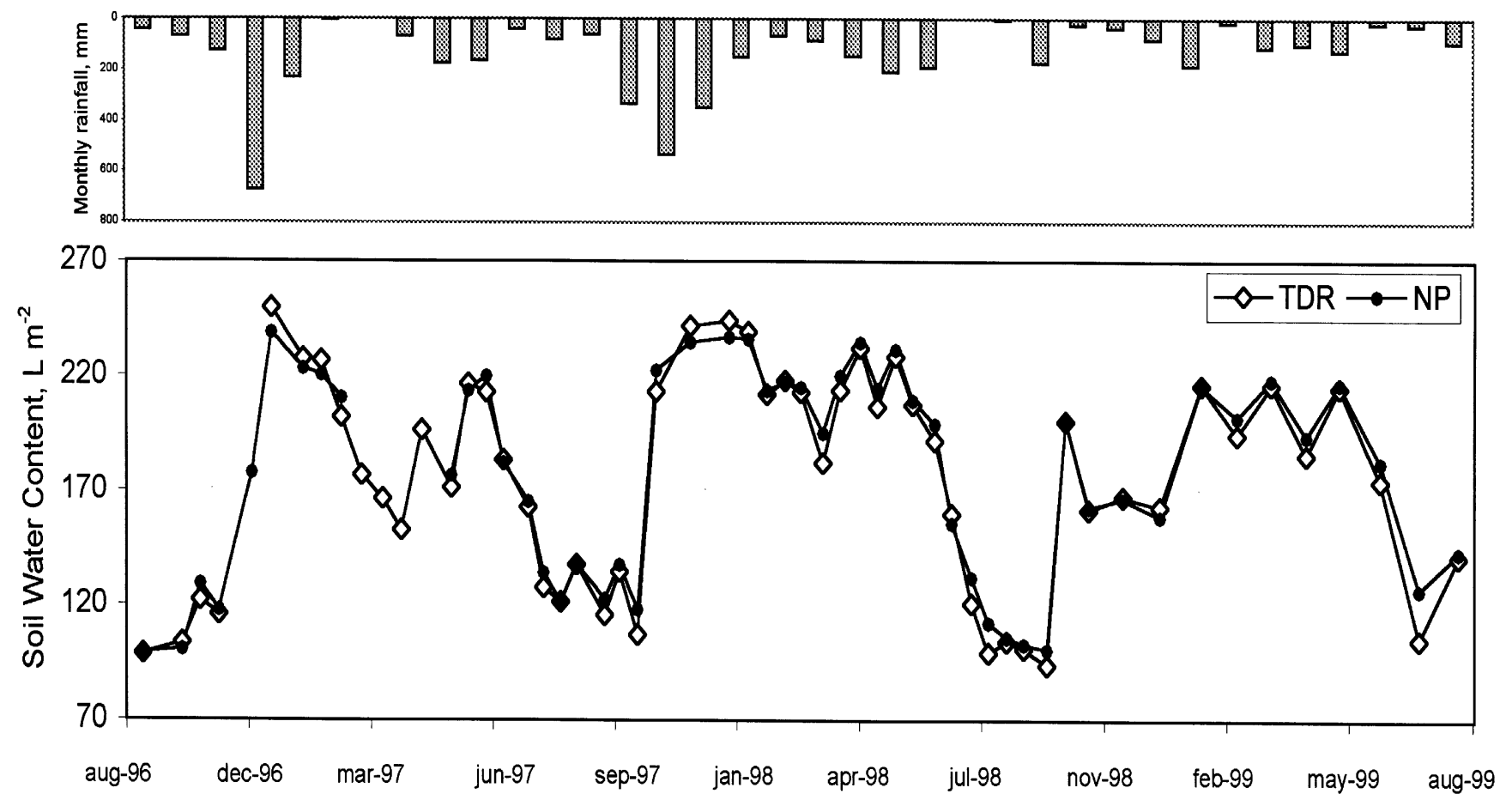

Figure 3. Seasonal variation of the soil-water contents (first $-80-\mathrm{cm}$ of depth) along 3 years, measured by two methods: TDR and neutron probe. Data about monthly rainfall are also shown as bars.

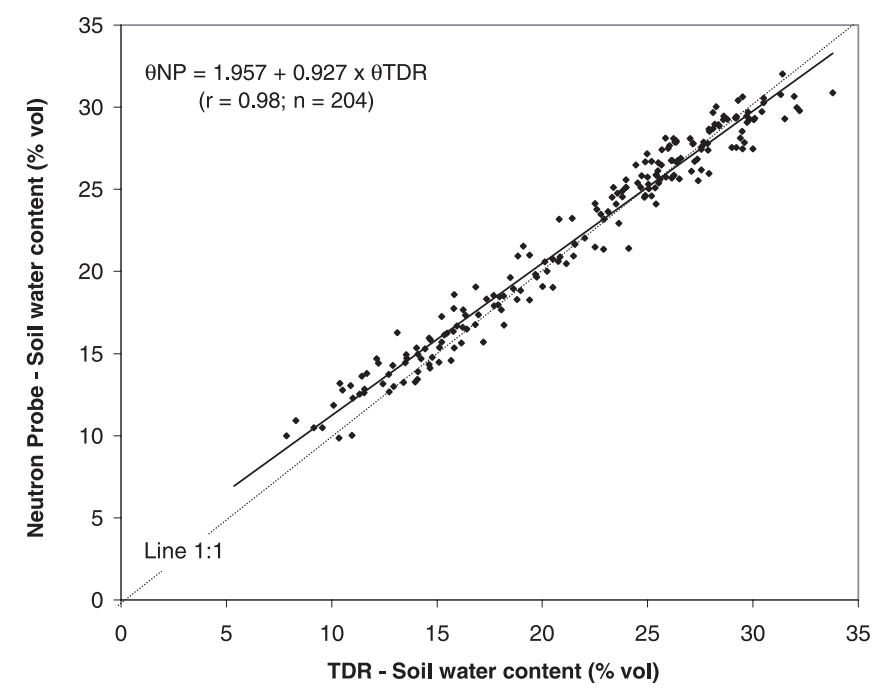

Figure 4. Lineal regressions between values volumetric water content of the soil studied, measured with two indirect methods: TDR and neutron probe.

moisture determinations. Topp et al. [28] concluded that both methods are equal when rods longer than $10 \mathrm{~cm}$ are used. Furthermore, in a laboratory study Yoder et al. [34] failed to find significant differences between the NP and 4-rod TDR techniques for a broad range of water contents; however, those authors did find significant differences when using 2-rod TDR probes, with which they obtained poorer results.

By contrast, we observed an important bias with respect to the 1:1 line in the low water content range (figure 4). Indeed, on applying two-way ANOVA, a significant difference between both data sets was found (degrees of freedom $=1$; 201; $P=8.2 \times 10^{-6}$; table III); TDR afforded slightly underestimated values of $\theta$ as compared to NP ( 0.218 versus $\left.0.222 \mathrm{~cm}^{3} \mathrm{~cm}^{-3}\right)$. Salas et al. [25] also found that TDR underestimated $\theta$.

\subsubsection{Comparison of soil moisture by ranges}

A significant interaction was found between the range of $\theta$ and probe type in the ANOVA analysis (d.f. $=3 ; 200 ; P=$ $1.2 \times 10^{-8}$; table $\left.I I I\right)$. From analysis of the interaction, we found that only for a low range of $\theta\left(0.08-0.14 \mathrm{~cm}^{3} \mathrm{~cm}^{-3}\right)$ were the differences significant (d.f. $=1 ; 200 ; P=0.007)$, TDR underestimating the $\theta$ values. At higher $\theta$, non-significant differences were found (table III).

Other authors have also reported that the similarity of the results varies as a function of the water content, although with different conclusions. Yoder et al. [34] found that the resolution of TDR was better for high moisture contents. By contrast, Topp et al. [28] observed that the TDR technique overestimated $\theta$ for high water contents. Jacobsen and Schjonning [9], using different calibrations methods for TDR, also obtained a higher bias with higher $\theta$ values. Finally, Salas 
Table III. Summary of the ANOVA results (two-way ANOVA with paired-values): (a) Probe type and depth (0-20, 20-40, 40-60 and $60-80 \mathrm{~cm}$ ); (b) Probe type and range of soil moisture $(0.08$ $0.14,0.14-0.21,0.21-0.28$ and $0.28-0.35 \mathrm{~cm}^{3} \mathrm{~cm}^{-3}$ ); (c) Probe type and period (wetting, drying, and steady state).

\begin{tabular}{lccl}
\hline Effect & D.f. & F & $P$ \\
\hline Probe type & $1 ; 201$ & 20.98 & $8.210^{-6}$ \\
Depth $\times$ Probe type & $3 ; 200$ & 2.53 & 0.058 \\
Range $\theta \times$ Probe type & $3 ; 200$ & 14.62 & $1.210^{-8}$ \\
Period $\times$ Probe type & $2 ; 201$ & 14.63 & $1.210^{-6}$ \\
\hline D.f $:$ d
\end{tabular}

D.f.: degrees of freedom.

et al. [25] obtained TDR data that underestimated $\theta$ for any range of soil water contents.

\subsubsection{Comparison by periods}

It is well known that, apart from the water content, TDR reading depends on the size of the pores containing the water [17]. This is very important when the soil is undergoing drying and wetting because soil pores that contain water differ between these periods. Therefore, the results may thus differ even though the same water content is involved, depending on whether the soil is being wetted or being dried.

To carry out this comparison, we grouped the data in three categories as a function of the variation in $\theta$ between two consecutive readings (fortnightly): drying, wetting, and steady-state (when the difference was lower than $4 \mathrm{~cm}^{3} \mathrm{~cm}^{-3}$ ). The significant interaction found between period and probe type in the ANOVA analysis (d.f. $=2 ; 200 ; P=1.2 \times 10^{-6}$; table III) is proof of the importance of pore size in the TDR reading. The bias found when the soil was drying $\left(-0.8 \mathrm{~cm}^{3} \mathrm{~cm}^{-3}\right)$ was greater than in other periods $(-0.06$ when undergoing wetting, and 0.10 at steady-state). We checked that this result was not determined by the difference in range of $\theta$ between the three defined periods; the ANOVA revealed a non-significant co-variance between periods and the range of $\theta(d . f .=2 ; 200 ; P=0.296)$.

\subsubsection{Comparison by depths}

A non-significant interaction was found between depth and probe type in the ANOVA analysis (d.f. $=3 ; 200 ; P=0.058$; table III). Moreover, very good correlations were found between TDR and NP readings at all depths. Nevertheless, the results of the regressions improves with depth (table $I V$ ) and the differences observed at $0-20 \mathrm{~cm}$ were slightly higher (although non-significant) than those at deeper layers, probably because the degree of wetting/drying is more pronounced at $0-20 \mathrm{~cm}$. Also, the increase in soil bulk-density with depth, which leads to greater soil homogeneity $[11,15]$, could contribute to the improvement of the results with depth. Salas et al. [25] also observed greater differences between the gravimetric and TDR techniques for the first $30 \mathrm{~cm}$ of soil depth (greater heterogeneity).
Table IV. Resume of results of the lineal regressions between soil water-content measured with TDR and neutron probe, at different depths $\left(\theta_{\mathrm{NP}}=\mathrm{a}+\mathrm{b} \times \theta_{\mathrm{TDR}}\right)$.

\begin{tabular}{lcccc}
\hline Depth & $\mathrm{a}$ & $\mathrm{b}$ & $r^{2}$ & Number \\
\hline $0-80 \mathrm{~cm}$ & 1.9574 & 0.9271 & 0.9682 & 204 \\
$0-20 \mathrm{~cm}$ & 2.9538 & 0.8855 & 0.9755 & 51 \\
$20-40 \mathrm{~cm}$ & 2.3155 & 0.9108 & 0.9518 & 51 \\
$40-60 \mathrm{~cm}$ & 1.1767 & 0.9508 & 0.9679 & 51 \\
$60-80 \mathrm{~cm}$ & 0.2976 & 0.9989 & 0.9764 & 51 \\
\hline
\end{tabular}

\subsection{Temporal variation of the moisture profile}

Considerable interannual variation in soil water contents was observed (figure 3). The rainfall over the three-year study period was 1655, 2104, and $957 \mathrm{~mm}$, respectively.

Figure 3 also shows a clear seasonal variation, characteristic of Mediterranean climate. It is possible to observe two well-differentiated periods among all the years studied: overall, there is a wet period lasting approximately from November to June, (depending on the year in question) and a dry period from June to November [31].

A more reduced temporal variation in $\theta$ was seen in deep layers since the surface is re-humidified and dried more often; indeed every time it rains. Standard temporal deviations were

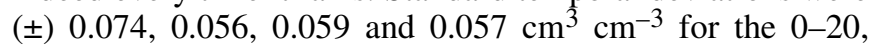
20-40, 40-60 and 60-80 cm layers, respectively. This is a common phenomenon and has been described by many authors [12, 19]. It is an effect involving two processes: Evaporation from the soil surface, and water uptake by roots; mainly in the upper $-40 \mathrm{~cm}$ (table II). Considering only the spatial variation, the standard deviations also decreased with depth: ( \pm ) $0.026,0.019,0.016$, and $0.015 \mathrm{~cm}^{3} \mathrm{~cm}^{-3}$ for $0-20$, 20-40, 40-60 and 60-80 cm, respectively.

Generally, the soil water content increased with depth, although in some short periods the opposite was found, mainly with the first rainfall (autumn; figure 5). Soil humidity, in terms of both extreme and mean values, increased gradually with the depth of the soil; the minimum value was found at the surface, as expected (owing to a more marked drying process at the soil surface). After the dry summer period and continuous rainfalls, there are two sources of soil wetting: one from the soil surface downwards, and the other from deep layers upwards, beside the lateral water displacement described by other authors [1]. This demands the prior existence of a phenomenon termed "flowing off" by Rode [22], which involves excess water rapidly flowing down to deep layers due to excessive water weight and/or through preferential flow paths [16].

\section{CONCLUSIONS}

Significant differences were observed, mainly at low soilwater content values, between the NP and TDR readings. The soil-moisture values obtained with the former method were in general slightly higher than those obtained using the latter 

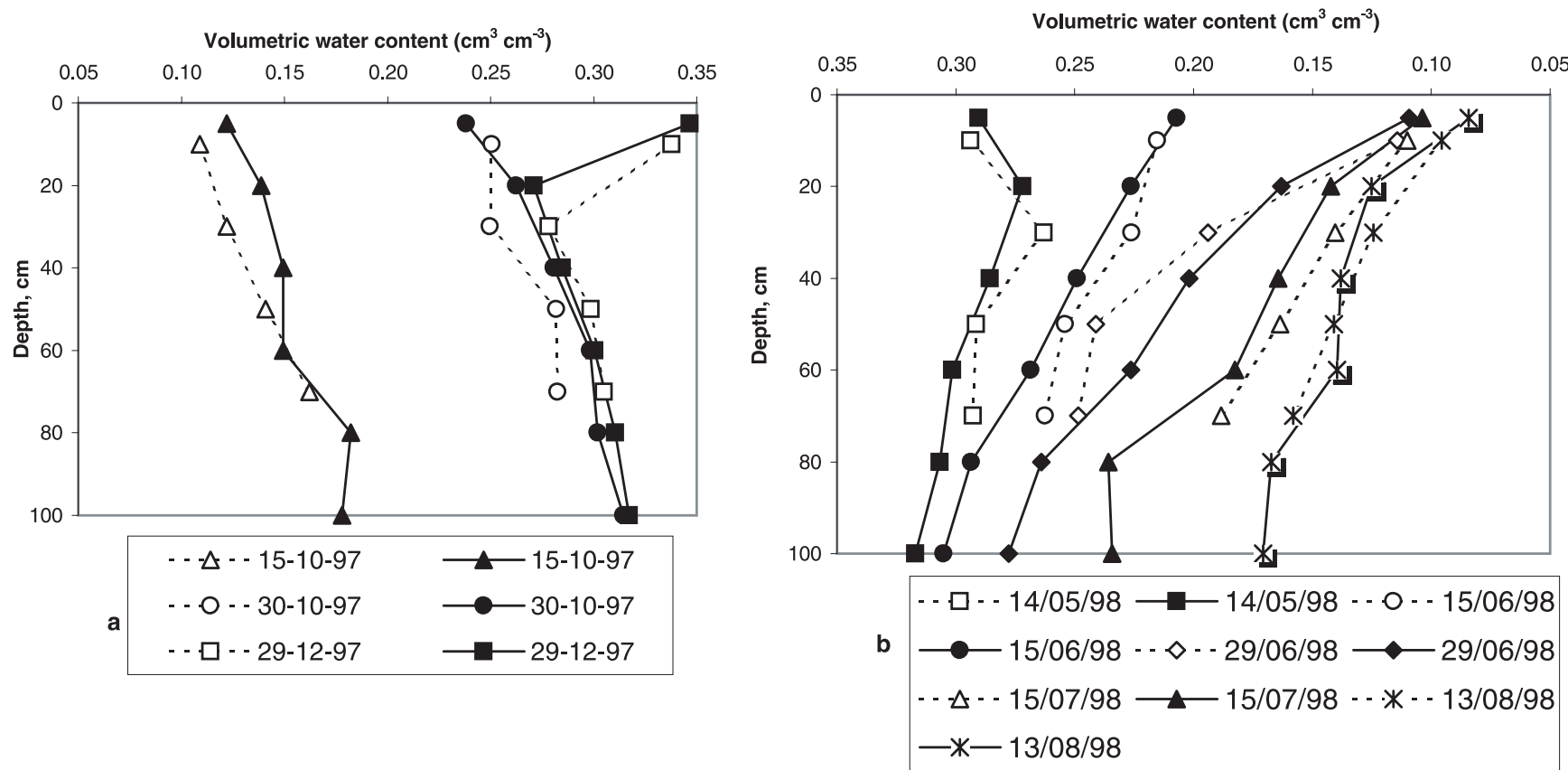

Figure 5.- Soil-moisture profile obtained with TDR in two different periods: (a) water recharge of the soil; (b) drying process of the soil. Data obtained with both methods are compared: Neutron probe (black symbol and solid line) and TDR (white symbol and dotted line).

technique. However, the bias was low, with an average difference of $-0.004 \mathrm{~cm}^{3} \mathrm{~cm}^{-3}$, the range being 0.029 to $-0.032 \mathrm{~cm}^{3} \mathrm{~cm}^{-3}$.

Nevertheless, considering the soil-water content throughout the soil profile, the differences between both methods were non-significant. Thus, both techniques are interchangeable and it is therefore possible to avoid the potential risk of radioactive hazard when using the NP method.

The differences between the TDR and NP readings decreased with both increasing depth and water content. This may reflect the influence of the size of pores containing water at the time when TDR measurements are being taken. It could be also explained (at least partially) in terms of the strong spatial variation in $\theta$ measurements in the upper soil layers (the same point of the soil is not measured by both techniques), in addition to the frequent temporal variability and the precision of the instruments. As observed by Topp and Davis [26], the sources of error due to instrumental precision and spatial variability cannot be separated.

The results of the TDR measurements could be improved by using custom calibration to fit, for instance, the value of $\alpha$, because this parameter varies linearly with soil bulk-density and may be correlated with many other soil-properties (such as porosity, mineralogy and particle-size distribution [35]).

Acknowledgements: The authors wish to thank the "Junta de Castilla y León" for allowing them the use of the forest plot, the European Union (PROTOS/TERI Project) and the Spanish CICYT Fund for financial support. The invaluable technical assistance Jesús Hernández and Miguel Tapia is acknowledged.

\section{REFERENCES}

[1] Cermak J., Prax A., Water balance of a southern Moravian floodplain forest under natural and modified soil water regimes and its ecological consequences, Ann. Sci. For. 58 (2001) 15-29.

[2] Dobson M.C., Ulaby F.T., Hallikainen M.T., El-Rayes M.A., Microwave dielectric behaviour of wet soil. Part II: Dielectric mixing models, IEEE Trans. Geosci. Remote Sens. GE- 23 (1985) $35-46$.

[3] F.A.O., World Reference Base for Soil Resources, F.A.O., Rome, 1998.

[4] Field C.B., Biological scaling of carbon gain to stress and resource availability, in: Mooney H.A., Winner W.E., Pell E.J. (Eds.), Response of plants to multiple stresses, Academic Press, San Diego 1991, pp. 35-65.

[5] Gardner C.M.K., Bell J.P., Cooper J.D., Dean T.J., Gardner N., Hednett M.G., Soil water content, in: Smith K.A., Mullins C.E. (Eds.), Soil Analysis Physical Methods, Marcel Dekker, New York, 1991, pp. 1-74.

[6] Gaskin G.J., Miller J.D., Measurement of soil water contents using a simplified impedance measuring technique, J. Agric. Engineer. Res. 63 (1996) 153-160.

[7] Haverkamp R.E., Vauclin M., Vachaud G., Error analysis in estimating soil water content from mention probe measurements. I. Local standpoint, Soil Sci. 137 (1984) 78-90.

[8] International Atomic Energy Agency. Comparison of soil water measurement using the neutron scattering, time domain reflectometry and capacitance methods, IAEA-TECDOC-1137, Vienna 2000, $165 \mathrm{p}$.

[9] Jacobsen O.H., Schjonning P., Field evaluation of time domain reflectometry for soil-water measurements, J. Hydrol. 151 (1993) 159-172.

[10] Jacobsen O.H., Schjonning P., Comparison of TDR calibration functions for soil water determination, in: Petersen L.W., Jacobsen O.H. (Eds.), Time-Domain Reflectometry Applications in Soil Science, Proceedings of the Symposium, Tjele, Denmark, Sept. 1995, SP report 11. Tjele, 1995, pp. 25-33. 
[11] Kutilek M., Nielsen D.R., Soil Hydrology Geoecology, textbook, Catena Verlag-Cremlingen, Germany, 1994.

[12] Ladekarl U.L., Estimation of the components of soil water balance in a Danish oak stand from measurements of soil moisture using TDR, For. Ecol. Manage. 104 (1998) 227-238.

[13] Ley T.W., Stevens R.G., Topielec R.R., Neibling W.H., Soil water monitoring and measurement, Pacific-Northwest Co-operative Extension Publ. 475 (1994) 1-36.

[14] Mastrorilli M., Katerji N., Rana G., Ben Nouna B., Daily actual evapotranspiration measured with TDR technique in Mediterranean conditions, Agric. For. Meteorol. 90 (1998) 81-89.

[15] Moreno G., Gallardo J.F., Ingelmo F., Cuadrado S., Hernández J., Soil-water budget in four Quercus pyrenaica forest across a rainfall gradient, Arid Soil Res. Rehabil. 10 (1996) 65-84.

[16] Moreno G., Gallardo J.F., Schneider K., Ingelmo F., Water and bioelement fluxes in four Quercus pyrenaica forests along a pluviometric gradient, Ann. Sci. For. 53 (1996) 625-639.

[17] Noborio N., Measurement of soil water content and electrical conductivity by time domain reflectometry: a review, Comput. Electron. Agric. 31 (2001) 213-237.

[18] Noborio K., McInnes K.J., Heilman J.L., Measurements of soil water content, heat capacity and thermal conductivity with a single TDR probe, Soil Sci. 161 (1996) 22-28.

[19] Rabadà D., Gallart F., Monitoring soil-water content variability in the Cal Parisa basin (Alt Llobregat) with TDR. Experimental design and first results, Acta Geol. Hispan. 28 (1993) 85-93.

[20] Rambal S., The differential role of mechanisms for drought resistance in a Mediterranean evergreen shrub: a simulation approach, Plant Cell Environ. 16 (1993) 35-44.

[21] Rambal S., Debussche G., Water balance of Mediterranean ecosystems under a changing climate, in: Moreno J.C., Oechel W.C. (Eds.), Global Change and Mediterranean-type ecosystems, Ecological studies 117, Berlin: Springer-Verlag, 1995, pp. 386-407.

[22] Rode A.A., Soil Science, U.S. Department of Commerce, Washington DC, 1955.

[23] Roth C.H., Malicki M.A., Plagge R., Empirical evaluation of the relationship between soil dielectric constant and volumetric water content and the basis for calibrating soil moisture measurements by TDR, J. Soil Sci. 43 (1992) 1-13.

[24] Roth K., Schulin R., Flühler H., Attinger W., Calibration of time domain reflectometry for water content measurement using a composite dielectric approach, Water Resour. Res. 26 (1990) 2267-2273.

[25] Salas R., Molina E., Bouldin D.R., Calibration of the time-domain reflectometer and determination of the volumetric water content of the soil profile in an Ultisol of Costa Rica, Commun. Soil. Sci. Plant Anal. 27 (1996) 2433-2442.

[26] Topp G.C., Davis J.L., Time-Domain reflectometry (TDR) and its application to irrigation scheduling, in: Hillel D. (Ed.), Advances in Irrigation, Academic Press, New York, Vol. 3, 1985, pp. 107-127.

[27] Topp G.C., Davis J.L., Annan A.P., Electromagnetic determination of soil water content: Measurements in coaxial transmission lines, Water Resour. Res. 16 (1980) 574-582.

[28] Topp G.C., Davis J.L., Bailey W.G., Zebchuk W.D., The measurement of soil water content using a portable TDR hand probe, Can. J. Soil Sci. 64 (1984) 313-321.

[29] Turrión M.B., Gallardo J.F., González M.I., Extraction of soilavailable phosphate, nitrate, and sulphate ions using ion exchange membranes and determination by ion exchange chromatography, Soil. Sci. Plant Anal. 30 (1999) 1137-1152.

[30] Vachaud G., Royer J.M., Cooper J.D., Comparison of methods of calibration of a neutron probe by gravimetric or neutron-capture model, J. Hydrol. 34 (1977) 343-355.

[31] Vicente M.A., Gallardo J.F., González M.I., Evolution of soil water in a Mediterranean forest ecosystem ("Sierra de Gata", Western Spain), in: Bech J. (Ed.), 6th International Meeting: Soils with Mediterranean Type of Climate, Extended Abstracts, Barcelona, Spain, July 4-9, 1999, University of Barcelona, Spain, 1999, pp. 71-73.

[32] Weast R.C. (Ed.), Handbook of Chemistry and Physics, 68th edn. Boca Ratón, Florida, C.R.C. Press, 1987.

[33] Young M.H., Wierenga P.J., Mancino C.F., Large weighing lysimeters for water use and deep percolation studies, Soil Science 161 (1996) 491-501.

[34] Yoder R.E., Johnson D.L., Wilkerson J.B., Yoder D.C., Soil-water sensor performance, Appli. Engineer. Agric. 12 (1998) 121-133.

[35] Zakri T., Laurent J.P., Vauclin M., Theoretical evidences for "Lichtenecker's mixture formulae" based on the effective medium theory, J. Phys. D: Appl. Phys. 31 (1998) 1589-1594.

[36] Zegelin S.J., White I., Jenkins D.R., Improved field probes for soil water content and electrical conductivity measurements using TDR, Water Resour. Res. 25 (1989) 2367-2376. 